\title{
Los sefarditas en el Norte de Africa
}

Hans-Ludwig Dankwardt

Archivo Central del Ministerio de Relaciones con las Cortes y la Secretaría de Gobierno

Quiero agradecer a la Dirección Provincial del Ministerio de Cultura en Melilla, la invitación que me han hecho, y que me ha brindado la oportunidad de conocer esta interesante ciudad y aprender de los conocimientos expuestos en este Seminario.

Asimismo quiero agradecer la cooperación que el Archivo de la Presidencia me ha proporcionado a lo largo de mi trabajo de investigador.

En la actualidad estoy preparando mi tesis doctoral sobre las relaciones hispano-árabes e Israel.

Con tal finalidad he investigado en el Archivo Central del Ministerio de Relaciones con las Cortes y la Secretaría del Gobierno y también en el del Ministerio de Asuntos Exteriores.

En ambos archivos he encontrado documentos que puedo utilizar para mi tesis. Algunos pueden probar la importancia de Melilla para la emigración clandestina de los judíos marroquíes de 1959 a 1961.

Estos documentos quisiera presentarlos a ustedes después de una pequeña introducción sobre las relaciones entre España y los sefarditas.

El decreto de expulsión de 31 de marzo de 1492 daba, a los que no quisieran convertirse, cuatro meses de plazo para abandonar la Península. Los que lo hicieron se dirigieron a Portugal, al Norte de Africa y 
al Mediterráneo oriental, donde se conservaron la lengua y algunas tradiciones castellanas hasta el siglo XIX.

Durante este tiempo la presencia judía en España era mínima y desorganizada.

El primer reencuentro con los judíos fue el de las tropas españolas en Marruecos, en 1859-60, cuando se encontraron en Tetuán con personas que hablaban español y que los recibían como liberadores de los musulmanes.

El testimonio más inmediato es el del poeta, novelista y periodista Pedro Antonio de Alarcón, quien publica aquel mismo año el Diario de un testigo de la guerra de Africa.

Todo ello va creando un clima de admiración hacia los judios, en el que se combinan elementos nacionales y afectivos.

Algunos políticos e intelectuales (Castelar, etc.) e incluso el rey Alfonso XII pensaban, con bastante desconocimiento de la realidad, que la relación con los judíos sefarditas podría servir al engrandecimiento de España, aprovechando la influencia mundial que significaban los judíos extendidos por todo el mundo.

Más tarde, las campañas del médico Angel Pulido Fernández son, en especial, instrumento del acercamiento cultural a las comunidades judeoespañolas.

Sus libros, Los judios españoles y el idioma castellano y, Los españoles sin patria y la raza sefardí, pudieron sensibilizar a la sociedad española respecto a los problemas de la comunidad sefardita en el extranjero.

Creo que es bien sabido que el General Franco puso de nuevo en vigor una ley de 1924 que otorgaba a los sefarditas el derecho de regresar de nuevo a España cuando el gobierno del Tercer Reich puso en práctica su plan de deportación y exterminio de los judíos sefarditas.

El General Franco tenía que agradecer algunas cosas a los judíos. Cuando la Guerra Civil estalló en 1936, las comunidades hispano-judías y el barrio hebreo de Tetuán en Marruecos se pusieron inmediatamente al lado de Franco, que pocos años después premió esta actitud. 
En 1961, la población judía en Marruecos se calculaba en unas 250.000 personas. La mayoría huyó a Israel, a Francia y a España, en menor número, en vista de las medidas discriminatorias del gobierno marroquí que les negaba todo visado de salida.

En Tánger se pretendió retirar los pasaportes a toda la población hebrea, causando grave malestar entre la colonia judía de Marruecos.

Fez había sido en los años anteriores un punto de huida de judíos, quienes, a treinta kilómetros de $\mathrm{Fez}$, encontraban la montaña bereber, y ya de ahí a través del Rif, llegaban a Melilla para partir a Israel.

Por otra parte era un hecho conocido y comprobado en Fez y Mequinés que el marroquí israelita que solicitaba un pasaporte tenía que pagar a la policía un tributo que variaba entre 10 y 15.000 francos.

En estas condiciones, los judíos locales prefieren la emigración clandestina aun conociendo los riesgos que llevaba consigo.

El Cónsul de España en Fez, José Luis Xifra de Ocerín, escribe en una carta al Ministerio de Asuntos Exteriores de 16 de diciembre de 1961, que era raro el día en que no se reciben pasaportes extendidos a nombre de Salomón Levy, Moisés Cohn, David Mordochi, etc.

"Generalmente lo humilde de sus profesiones, no explica cómo una familia entera puede trasladarse 'de vacaciones' a España, $y$ en el mes de diciembre.

En realidad lo que ocurre es lo siguiente:

Las autoridades locales han permitido la contrata de obreros para trabajar en Canadá. Los contratistas son hebreos y contratan tan sólo hebreos.

El contrato es verbal y no suele pasar de una conversación más o menos como sigue:

- ¿Quieres irte?

- Sí.

- Ten listo todo el jueves. 
El contratado vende lo que puede (en general a precio irrisorio) para solicitar su pasaporte (que ahora le es concedido con facilidad), obtiene en el Consulado de España en Fez su visado para España y en el día señalado, marcha con su familia hacia la Tierra Prometida, vía Ceuta, Algeciras, Gibraltar.

No hay duda de que las autoridades locales conocen perfectamente estas actividades y saben que 'ir a Canadá' quiere decir 'ir a Israel'.

Pero lo permiten, probablemente por haber recibido órdenes de Rabat".

El rey Hassan II ha pedido préstamos a los Estados Unidos. Estos se le conceden tan sólo si deja salir del país a toda la población israelita.

En la madrugada del día 11 de enero de 1961, naufragó frente a las costas de Alhucemas un barco denominado "Pisces" o "Price", de bandera hondureña, a consecuencia del temporal reinante o quizás de un sabotaje político.

De los 42 ocupantes sólo se salvaron 3, el capitán y dos tripulantes, todos ellos de nacionalidad española.

El barco había zarpado de Melilla con dirección a Gibraltar, y sin duda era uno de los que se dedicaban al transporte clandestino de judíos marroquíes con dirección a Palestina.

La prensa española y extranjera dio cuenta del naufragio.

En el Consejo Nacional del Partido del Istiglal, El Fassi pronunció las siguientes palabras que paso a leer textualmente:

"España permite el empleo de Melilla como centro de conspiración sionista para la huida de connacionales judios marroquies a Israel sin pasaporte marroqui y sin la aprobación de la autoridad marroquí. 
Ullimamente se ha descubierto un barco español hundido en los límites de Melilla llevando a bordo más de cuarenta israelitas marroquies...

El capitán de la nave, que es español también, ha sido detenido y ha declarado que ésta no es la primera vez, ni el primero de sus viajes y contrabando...".

En vista de lo anteriormente dicho, surge la siguiente pregunta:

¿Por qué tolera el General Franco la emigración clandestina de Melilla y acepta una quiebra en las relaciones hispano-árabes?

Posibles explicaciones:

Primera:

Durante el siglo XIX España era el único país europeo que se plantea la aceptación o rechazo de los judíos como un problema nacional, en tanto que para el resto de los paises era sólo un problema humanitario y de politíca contemporánea.

En este sentido, la política del General Franco era la continuación de la de Alfonso XII, y de la del General Primo de Rivera.

Su política era prosefardita, aunque antisionista y contraria al Estado de Israel.

Segunda:

El General Franco confiaba en la enorme influencia que los judíos tienen en el mundo, especialmente en los Estados Unidos, país del que España dependía política y militarmente.

Muchas gracias por su atención y disculpen mi pronunciación. 
F $\quad$ U $\quad E \quad N \quad T \quad E \quad S$

GONZALEZ, Isidro: El Retorno de los Judios, Edición Nerea, 1991.

Ministerio de Asuntos Exteriores:

Legajo R 6527, Exp. 30, 33

Ministerio de Relaciones con las Cortes y la Secretaría del Gobierno. 